Artigo Original

\title{
DÉFICIT NUTRICIONAL EM RATOS WISTAR
}

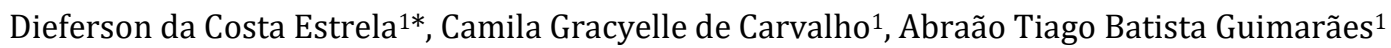 \\ 1 Instituto Federal Goiano - Campus Urutaí \\ *diefersonestrela@gmail.com
}

\section{N F O A R T I G O}

Histórico do artigo

Recebido: 02 abril 2016

Aceito: 19 maio 2016

Palavras chaves:

Desnutrição

Dieta de restrição

Proteina

\begin{abstract}
R E S U M O
A desnutrição causa diversos tipos de alterações, síndromes e doenças, afetando de forma generalizada ou não, vários parâmetros do indivíduo. Diante disso, o presente estudo objetivou avaliar os efeitos da restrição alimentar, em curto prazo, sobre parâmetros físicos, bioquímicos, hematológicos e histológicos em ratos Wistar. Para isso, fêmeas adultas com aproximadamente 90 dias de idade foram submetidas ao processo de restrição alimentar utilizando uma dieta contendo 6\% de proteína. Já os animais do grupo controle foram aqueles alimentados com dieta comercial padrão contendo 19\% de proteína. Após o estabelecimento da desnutrição, indicada pela diferença entre as massas corpóreas dos animais estudados, estes foram submetidos à eutanásia, tendo sido avaliada a massa absoluta e relativa do fígado, baço, coração, pâncreas, cérebro, rins e pulmões e glândulas suprarrenais, parâmetros bioquímicos e hematológicos, assim como a histologia do baço, fígado e rins desses animais. Os animais do grupo desnutrição apresentaram diminuição da concentração de leucócitos, triglicérides e lipoproteínas de muito baixa densidade (VLDL) e maior massa relativa do fígado, com presença de alterações histopatológicas incipientes quando comparados com os respectivos controles. Estes dados sugerem que a restrição alimentar, em curto prazo, é capaz de induzir o quadro de desnutrição e ocasionar sinais de alterações no fígado, mas não ocasiona alterações bioquímicas e hematológicas generalizadas.
\end{abstract}

\section{Introdução}

A alimentação é considerada fator primordial na rotina diária da humanidade, não apenas por se constituir em necessidade básica, mas principalmente porque a sua utilização de forma incorreta tornou-se problema de saúde pública, seja pelo excesso ou deficiência (WHO, 2011).

A falta de alimento ou a alimentação incorreta pode induzir ao quadro de déficit nutricional ou desnutrição, que segundo Lacerda et al. (2006) é caracterizado como uma condição patológica decorrente da falta de energia, proteínas e nutrientes, em variadas proporções. Há alguns anos a desnutrição tem sido associada à pobreza, baixa escolaridade materna, grande número de moradores em uma mesma residência, precárias condições de moradia e saneamento básico e com a idade materna inferior a 20 anos (OLINTO et al., 1993; MONTEIRO et al., 2009).

A Organização Mundial da Saúde (OMS) estima que a desnutrição contribua para mais do que um terço de todas as mortes de crianças no mundo, embora raramente seja listada como a causa direta (WHO, 2014). Além disso, a OMS adverte que mesmo níveis moderados de deficiências nutricionais, detectados por testes bioquímicos e/ou clínicos, podem provocar sérios prejuízos à saúde humana (WHO, 2005).
No Brasil, segundo o Ministério da Saúde (MS), no ano de 2001 existiam aproximadamente 923 mil pessoas em risco nutricional (BRASIL, 2001). Este número está regredindo nos últimos anos, e alguns estudos têm apontado que a desnutrição no Brasil diminuiu, como os trabalhos de Monteiro (2003) e Chagas et al. (2013). Em um trabalho desenvolvido em nível nacional, Monteiro et al. (2009) evidenciaram uma redução da desnutrição em crianças de até 5 anos de idade, de aproximadamente $50 \%$ em um período de aproximadamente 10 anos (1996 a 2006/7).

Apesar da diminuição, a desnutrição crônica continua sendo o principal problema de saúde pública na maioria dos países em desenvolvimento como o Brasil, Coréia, África do Sul, dentre outros (WHO, 2014). Nestes países ainda persistem elevadas prevalências de déficit de estatura associada à morbidade (PEDRAZA et al., 2013). Isso, somado à importância da redução das taxas do déficit de estatura em crianças através da suplementação efetiva com nutrientes e outros mecanismos, justificam a importância de conhecer melhor a desnutrição e suas implicações na saúde humana (PEDRAZA et al., 2013).

Com o intuito de compreender melhor os efeitos e consequências da desnutrição, estudos utilizando modelos 
experimentais têm despontado como importantes fontes de conhecimento. Gerude et al. (2002), em um estudo utilizando ratos Wistar evidenciaram que as principais alterações observadas no estômago de ratos submetidos ao déficit proteico são: atrofia da mucosa gástrica com evidente papilomatose, diminuição da secreção de ácido clorídrico e pepsina, causando enfraquecimento da barreira gástrica às bactérias.

Alterações físicas também vêm sendo relatadas, como perda de peso (ARAÚJO et al., 2003; ARAÚJO et al., 2005; PINHEIRO et al., 2008) e alterações significativas no crescimento corporal e de órgãos de ratos Wistar (VISMARA; FURLAN, 2007) e em camundongos Swiss (MALAFAIA, et al. 2009), diminuição da área do estômago em cerca de 20,1\% (em ratos Wistar) (MOLINARI et al. 2002) e diminuição significativa no peso intestinal e atrofia da mucosa intestinal, também em ratos Wistar (SILVA-GUSMAN, 2004). Além disso, o desenvolvimento de doenças como a esteatose hepática (WELTMAN et al. 1996; OKAN et al., 2002; ZAMIN-JUNIOR et al., 2009) e esteato-hepatite em ratos Wistar desnutridos, com efeitos semelhantes aos da esteato-hepatite alcoólica (WELTMAN et al. 1996), dentre outras, vêm sendo relacionados com a desnutrição.

Parâmetros bioquímicos também são prejudicados pela desnutrição, como mostra o estudo de Fagundes et al. (2007), no qual foi detectada hipoinsulinemia e discreta hipoglicemia na prole adulta de ratos Wistar, devido à restrição proteica durante a lactação. Xavier et al.(2007); Borelli et al. (2007); Malafaia et al. (2009) constataram diminuições significativas na concentração de proteínas totais em camundongos. Pinheiro et al. (2008) verificaram que as alterações na glicemia, insulinemia e leptinemia em ratos Wistar, causadas pela restrição proteica durante a gestação e/ou lactação podem ser passadas transgeracionalmente para a segunda geração dos filhotes. Além disso, parâmetros hematológicos são afetados, conforme demostrado por Ferrari et al. (1992) e Santos et al. (2004), nestes estudos, ratos Wistar tiveram significativa queda na concentração de leucócitos totais, caracterizando leucopenia, em situações de restrição alimentar e restrição proteica respectivamente.

Diante deste contexto, o objetivo desse trabalho foi avaliar os efeitos da restrição alimentar, em curto prazo, sobre parâmetros físicos, bioquímicos, hematológicos e histológicos em ratos Wistar.

Acredita-se que este estudo possa contribuir com a elucidação dos diversos e diferentes mecanismos relacionados com a desnutrição e seus efeitos orgânicos, assim como para o estudo da desnutrição no modelo experimental adotado.

\section{Material e métodos}

\subsection{Modelo experimental e dieta experimental}

Neste trabalho foram utilizadas 14 fêmeas de ratos da linhagem Wistar com aproximadamente 90 dias de vida, oriundas do Biotério Central da Universidade Federal de Goiás (Câmpus Samambaia), confinadas em gaiolas individuais do tipo metálica metabólica, para criação de ratos com área rigorosamente de acordo com as recomendações internacionais de piso e altura por espécie e grupos de animais, e mantidas sob fotoperíodo de $12 \mathrm{~h}$ à temperatura média de $25 \pm 2{ }^{\circ} \mathrm{C}$ no Laboratório de Pesquisas Biológicas do Instituto Federal Goiano - Câmpus Urutaí. Os animais foram distribuídos aletoriamente em relação à massa corpórea em dois grupos experimentais: grupo controle (C) e grupo desnutrição (D). Realizou-se dois experimentos independentes, cada um com duração de 28 dias, totalizando 7 animais por grupo.

Os animais do grupo controle receberam dieta padrão (Nuvilab CR1 - Nuvital), contendo 19\% de proteína e o grupo desnutrição foi alimentado com dieta hipoproteica, contendo $6 \%$ de proteína conforme utilizado por Cabral (2013), fabricada pela empresa PragSoluções Comércio e Serviços Ltda. - ME. Na Tabela 1 podem ser observadas as composições das dietas utilizadas neste trabalho.

Dentre os modelos de indução do quadro de desnutrição, dois deles têm sido mais frequentemente utilizados, sendo eles a restrição do volume alimentar (FERRARI et al., 1992; VISMARA; FURLAN, 2007; MAZARETI; FURLAN, 2008) e a restrição proteica (CHAVES; MELLO, 2003; MALAFAIA et al., 2009; CABRAL, 2013). No presente trabalho optou-se por unir estes dois modelos. Desse modo, foi utilizada uma dieta deficiente em proteína (6\% de caseína), conforme utilizado por Cabral (2013), e o volume da dieta foi limitado a $50 \%$, conforme utilizado por Vismara e Furlan (2007) e Mazareti e Furlan (2008). Vale salientar que a restrição alimentar imposta ao grupo desnutrição foi calculada diariamente a partir da ingestão alimentar (IA) do grupo controle, sendo oferecido ao grupo desnutrição $50 \%$ da quantidade ingerida pelo grupo controle no dia anterior. Podese dizer que o modelo de desnutrição utilizado induz à condição de deficiência generalizada de nutrientes, com deficiência proteica mais severa que os demais nutrientes.

Tabela 1. Composição das dietas experimentais em gramas para cada $1000 \mathrm{~g}$ das dietas (g/kg) utilizadas no presente estudo. Urutaí, 2014.

\begin{tabular}{|c|c|}
\hline INGREDIENTES & HIPOPROTEICA(1) (g/Kg) \\
\hline Caseína(2) & 75 \\
\hline Amido de milho & 552 \\
\hline Amido dextrinizado & 130 \\
\hline Sacarose & 100 \\
\hline DL-metionina & 3,6 \\
\hline Mistura de sais(3) & 35 \\
\hline Mistura de vitaminas(4) & 10 \\
\hline Bitartarato de colina & 2,5 \\
\hline Celulose & 50 \\
\hline Óleo de milho & 40 \\
\hline
\end{tabular}


INGREDIENTES DA DIETA NORMOPROTEICA(5)

Milho integral moído, farelo de soja, farelo de trigo, carbonato de cálcio, fosfato bicálcico, cloreto de sódio, mistura de vitaminas, minerais e aminoácidos.

ESPECIFICAÇÕES (5)

NÍVEIS DE GARANTIA POR Kg DO PRODUTO (g/Kg) (5)

\begin{tabular}{lr} 
Umidade & 125 \\
\hline Caseína(2) & 220 \\
\hline Extrato etéreo & 40 \\
Mistura de sais & 90 \\
Matéria fibrosa & 70 \\
Cálcio & 10,2 \\
Fósforo & 8
\end{tabular}

\section{ENRIQUECIMENTO POR KG DO PRODUTO(5)}

Vitaminas: Vitamina A 13.000 UI; Vitamina D3 2.000 UI; Vitamina E 34 UI; Vitamina K3 3 mg; Vitamina B1 5 mg; Vitamina B2 6 mg; Vitamina B6 7 mg; Vitamina B12 22 g; Niacina 60 mg; Pantotene de cálcio 20 mg; Ácido fólico 1 mg; Biotina 0,05 mg; Colina $1900 \mathrm{mg}$.

Minerais: Zinco 60 mg; Cobre 10 mg; Iodo 2 mg; Selênio 0,05 mg; Cobalto 1,5 mg; Flúor 80 mg.

Aminoácidos: Lisina $12 \mathrm{~g}$; Metionina $4.000 \mathrm{mg}$.

Aditivos: BHT $100 \mathrm{mg}$.

(1) Dieta fabricada pela empresa PragSoluções Comércio e Serviços Ltda. - ME.

(2) 0 teor de proteína da caseína utilizada foi de aproximadamente $80 \%$.

(3) Adaptado de Reeves et al. (1993) - AIN-93G-MX.

(4) Adaptado de Reeves et al. (1993) - AIN-93-GX.

(5) Nuvital (2014).

As dietas foram oferecidas em forma de pellets, sendo ofertadas ad libitum para o grupo controle, conforme utilizado por Ritter et al. (2012) e Cabral (2013), e de forma restrita para o grupo desnutrição, conforme descrito anteriormente. Salienta-se que a dieta do grupo desnutrição foi oferecida em horários diferentes a cada dia, sendo estes distribuídos entre os três períodos do dia (manhã, tarde e noite), a fim de induzir o quadro de desnutrição e evitar adaptação do organismo ao quadro de restrição nutricional. A água foi oferecida ad libitum para ambos os grupos experimentais.

\subsection{Avaliação dos parâmetros físicos}

Após a divisão dos grupos experimentais, os animais passaram por um período de 7 dias de adaptação das dietas e condições experimentais, para apenas a partir desse período serem avaliados. Salienta-se que, durante este período de aclimatação os animais do grupo desnutrição receberam a dieta hipoproteica ad libitum.

Com o intuito de determinar os efeitos da restrição alimentar, em curto prazo, sobre as massas corpóreas dos animais, essas foram determinadas diariamente entre o $8^{\circ}$ e $28^{\circ}$ dia do experimento. Ao final do experimento, todos os animais foram submetidos à eutanásia, seguida de necropsia para retirada e pesagem do fígado, baço, coração, pâncreas, cérebro, rins e pulmões e glândulas suprarrenais.

Para todos os órgãos e glândulas foram avaliadas as massas absolutas e relativas. A massa relativa foi calculada a partir da razão órgão inteiro/massa corporal, conforme metodologia utilizada por Oliveira (2007) e Ritter et al. (2012).

\subsection{Avaliação dos parâmetros bioquímicos}

Visando avaliar os efeitos da restrição alimentar, em curto prazo, sobre alguns parâmetros bioquímicos, foram realizadas as dosagens séricas da glicemia, proteínas totais e frações e perfil lipídico. Os exames foram realizados em laboratório clínico comercial, localizado em Pires do Rio, GO.

Para a dosagem de glicemia, proteínas totais e frações e perfil lipídico foi utilizado o método automatizado A15 - Biosystems, conforme utilizado por Rodrigues et al. (2011) e Rahamtalla et al. (2012).

Salienta-se que para a realização das avaliações bioquímicas, os animais ficaram em jejum por no mínimo $12 \mathrm{~h}$ sendo coletadas $3 \mathrm{ml}$ de sangue através do rompimento da artéria braquial na região do plexo braquial e o sangue colocado em tubos de ensaio com capacidade de $5 \mathrm{~mL}$ sem anticoagulantes.

\subsection{Avaliação de parâmetros hematológicos}

$\mathrm{Na}$ avaliação de parâmetros hematológicos foi realizado o exame hemograma composto de eritrograma, leucograma e plaquetograma. 0 exame foi realizado em laboratório clínico comercial, localizado em Pires do Rio, GO.

0 hemograma foi realizado por meio do método automatizado ABX - Micros 60, conforme utilizado por Tomczak et al. (2010) e Urtiaga et al. (2013).

Para a realização do exame, os animais ficaram em jejum por no mínimo $12 \mathrm{~h}$, sendo coletadas $2 \mathrm{ml}$ de sangue através do rompimento da artéria braquial na região do plexo braquial e o sangue colocado em tubos de ensaio com capacidade de $5 \mathrm{~mL}$ com anticoagulante do tipo EDTA.

\subsection{Avaliação histológica}

Para realizar avalições histopatológicas, fígado, baço e rim de animais de ambos os grupos experimentais foram coletados no momento da eutanásia e fixados em formol tamponado $10 \%$, por no mínimo $48 \mathrm{~h}$ para posterior processamento e inclusão em parafina. Fragmentos de aproximadamente $1 \mathrm{~cm} 2$ foram processados em concentrações crescentes de álcoois, diafanizados em dois banhos de xilol, embebidos em dois banhos de parafina líquida a $60^{\circ} \mathrm{C}$, por $1 \mathrm{~h}$ em cada bateria e incluídos em parafina. Após 
estre procedimento os blocos de parafina foram cortados a 4 $\mu \mathrm{m}$ de espessura. Os cortes histológicos foram corados com hematoxilina-eosina (HE).

Ressalta-se as lâminas histológicas foram confeccionadas em laboratório de análises clínicas comercial, localizado em Goiânia. As análises dos cortes histológicos foram realizadas microscopicamente de forma qualitativa a fim de avaliar comparativamente as estruturas teciduais dos órgãos dos animais dos diferentes grupos experimentais.

\subsection{Análise estatística}

Todos os dados numéricos foram submetidos ao teste de normalidade de Anderson-Darling e, em seguida, submetidos ao Teste $\mathrm{t}$ de Student. As diferenças foram consideradas estatisticamente significativas quando os valores de $\mathrm{p}$ foram menores que $0,05(p<0,05)$. Para isso, foi utilizado o software estatístico Minitab® (MINITAB, 2003).

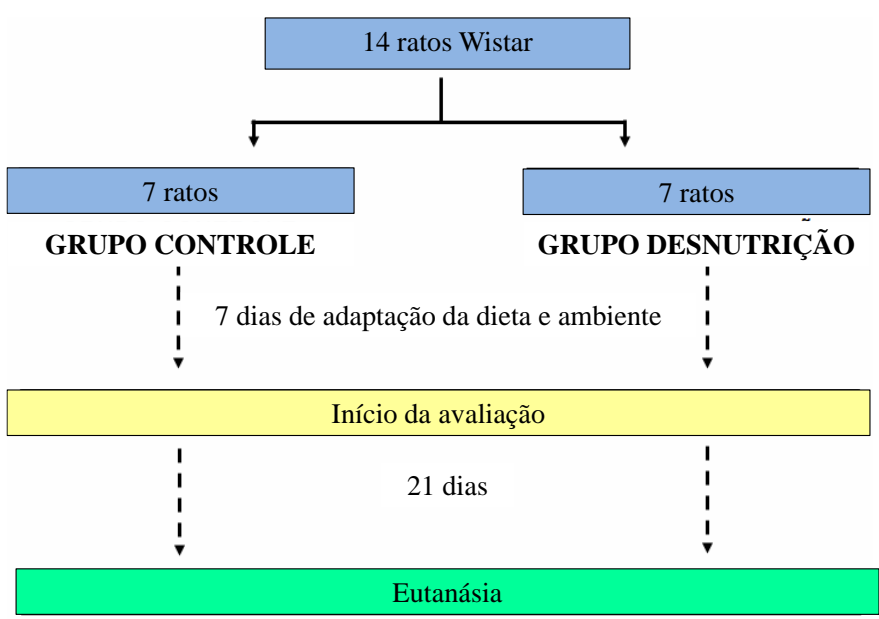

Figura 1: Delineamento experimental.

\section{Resultados e discussão}

Em relação à massa corporal dos diferentes grupos experimentais, observou-se diminuição significativa na massa corpórea dos animais do grupo desnutrição (Figura 1). Conforme mostrado na Figura 2, foi observada nítida alteração visual nos animais do grupo desnutrição, durante o período de restrição alimentar quando comparados aos animais do grupo controle.

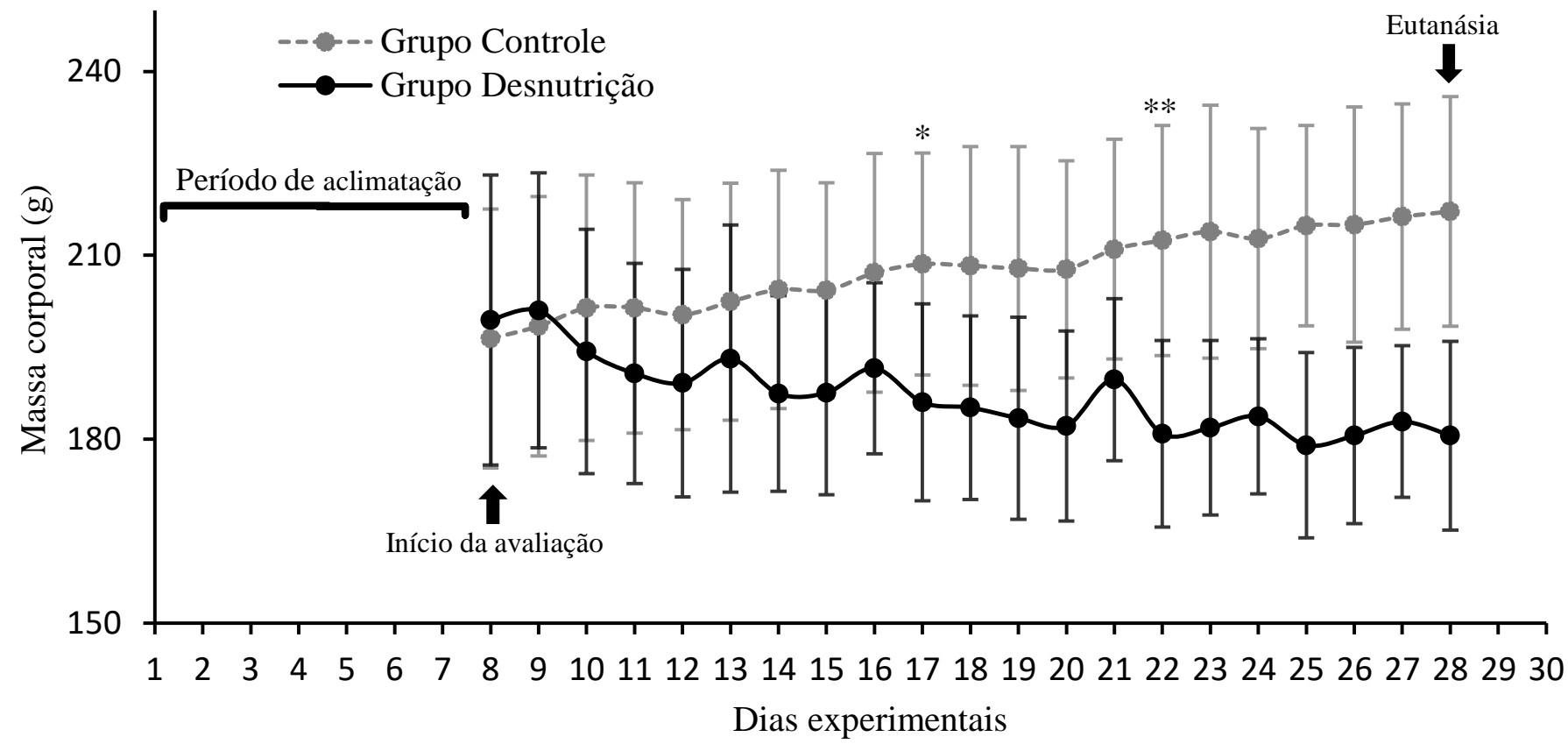

Figura 2: Variação da massa corpórea dos animais estudados. Os dados apresentados são expressos em média \pm desvio padrão. Diferenças entre os grupos são consideradas significativas * $(\mathrm{p}<0,05)$ ou ${ }^{* *}(\mathrm{p}<0,01)$. Diferença significativa a partir do $17^{\circ}$ dia. A análise estatística foi realizada pelo teste t de Student. Grupo Controle $(n=7)$ e desnutrição $(n=7)$. 

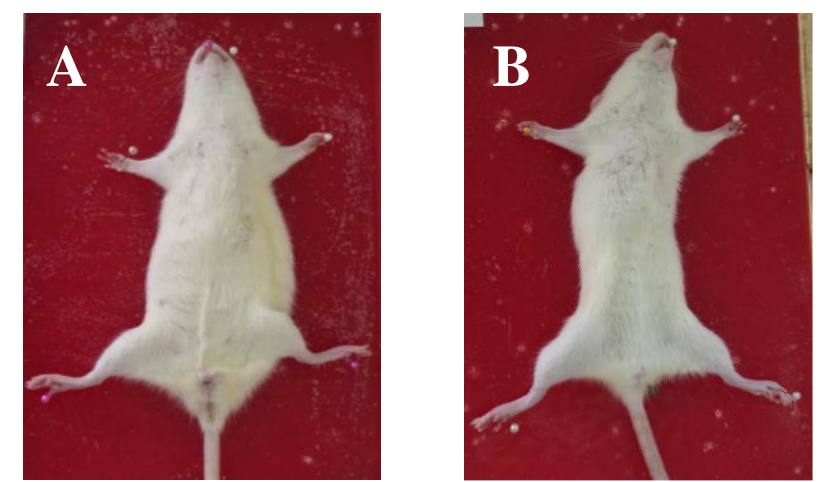

Figura 3. Aspecto visual representativo dos animais dos grupos controle (A) e desnutrição (B), registrado ao final do período experimental.

Estes resultados corroboram achados de outros autores que também evidenciaram diminuição significativa da massa corpórea dos animais submetidos à desnutrição (PINHEIRO et al., 2008; MALAFAIA et al., 2009; CABRAL, 2013). Observou-se que, no presente estudo, a restrição alimentar, mesmo em curto prazo, proporcionou redução da massa corpórea semelhante à verificada por outros autores, em protocolos experimentais de longos períodos de desnutrição.

Outros trabalhos desenvolvidos com ratas da linhagem Fisher sugerem a existência de clara associação entre a desnutrição e a massa corporal, em razão dos processos adaptativos, que acontecem para que o organismo se ajuste às condições nutricionais adversas, às quais o animal está sendo submetido (OLIVEIRA, 2007). Diante disso, é possível afirmar que a restrição alimentar utilizando dieta composta de $6 \%$ de proteína (caseína) foi eficaz na promoção do quadro de desnutrição experimental, uma vez que a redução da massa corporal pode ser utilizada como indicador básico dessa condição (SAWAYA, 2006).

A avaliação das massas absolutas dos órgãos entre os grupos estudados não revelou diferença entre os grupos experimentais (Figura 3). Sendo assim, três semanas de restrição alimentar e a desnutrição instalada durante este período mostrou-se insuficiente para acarretar perdas significativas na massa absoluta dos órgãos.

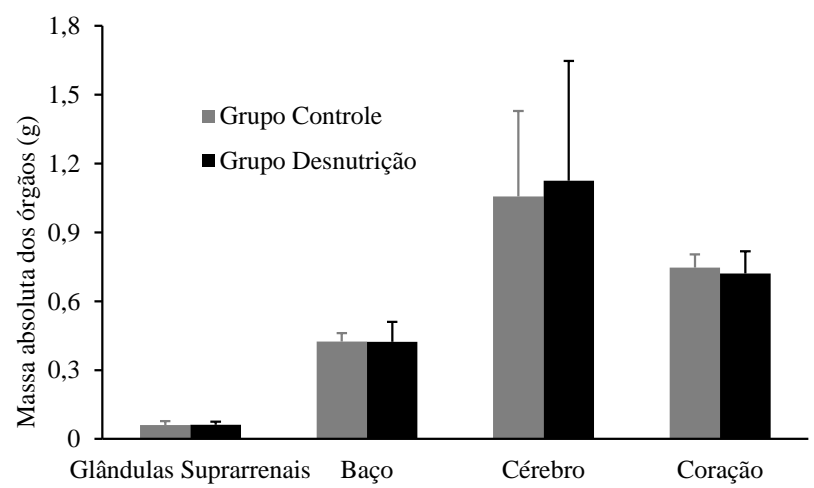

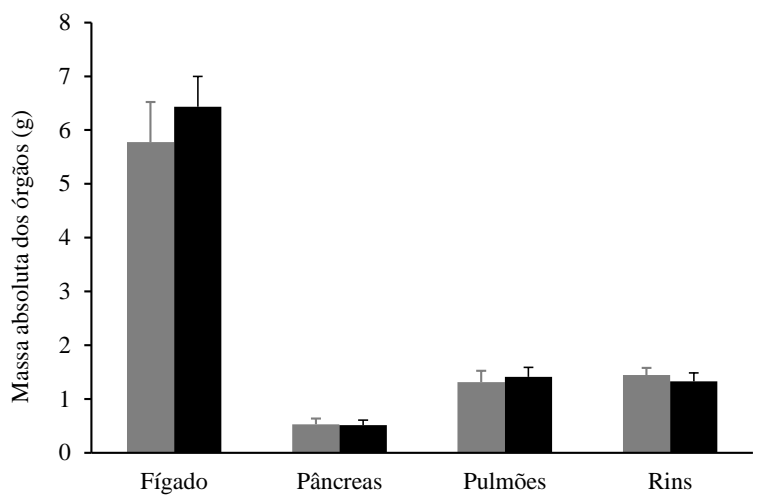

Figura 4: Massa absoluta dos órgãos dos animais estudados. Os dados apresentados são expressos em média + desvio padrão. Grupo Controle $(n=7)$ e desnutrição $(n=7)$ (dois experimentais independentes foram realizados).

Estes resultados corroboram os resultados encontrados por Malafaia et al. (2009), que não observaram diferenças significativas nas massas de alguns órgãos de camundongos Swiss, submetidos a dieta aproteica durante três semanas. Os mesmos autores observaram diferença significativa na massa do fígado e baço, diferindo assim, dos resultados do presente estudo. Contudo, tais diferenças podem ter sido ocasionadas pela ausência total de proteína na dieta utilizada pelos autores, diferente deste estudo, no qual a dieta continha $6 \%$ de caseína.

Quanto à avaliação da massa relativa dos órgãos, não foi observada diferença significativa para a maioria dos órgãos e glândulas analisados. Diferenças significativas foram observadas apenas para o fígado e pulmões (Figura 4).
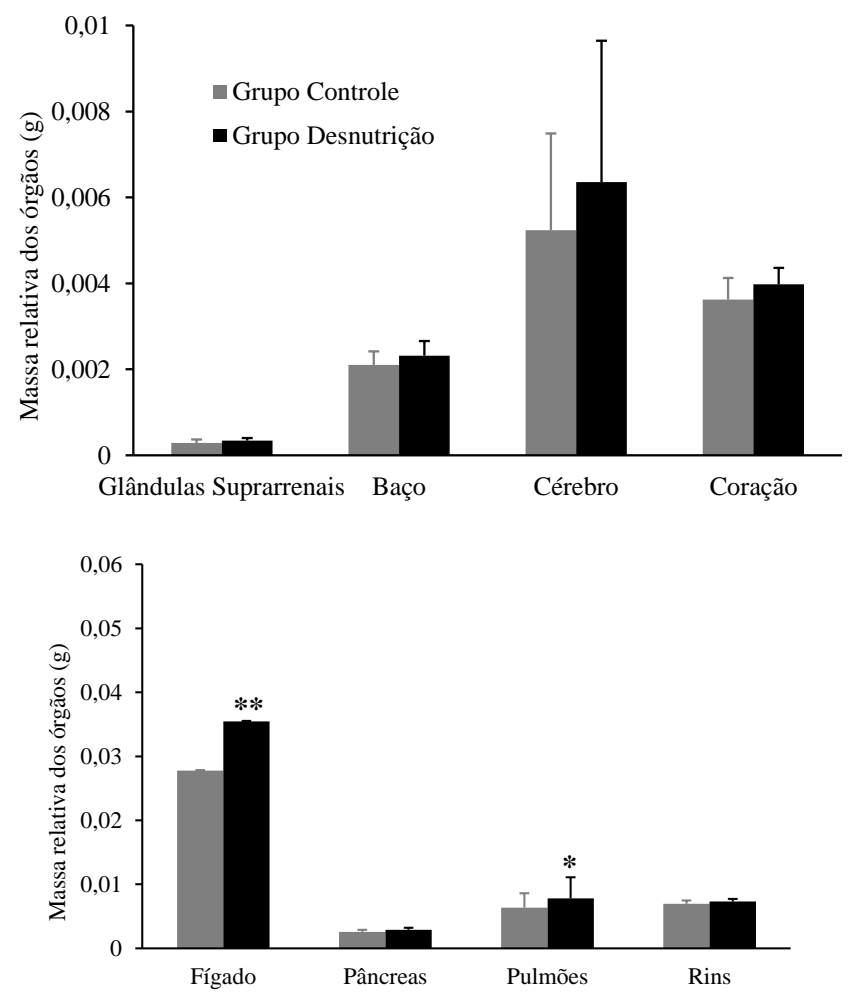

Figura 5: Massa relativa dos órgãos dos animais estudados. Os dados apresentados são expressos em média + desvio padrão. Diferenças entre os grupos são consideradas significativas ${ }^{*}(\mathrm{p}<0,05)$ ou ${ }^{* *}(\mathrm{p}<0,01)$. Grupo Controle $(\mathrm{n}=7)$ e desnutrição $(n=7)$ (dois experimentais independentes foram realizados). 
Estes resultados corroboram os achados de Mazareti e Furlan (2008) e Zamin-Junior et al. (2009) que também encontraram fígados com massas significativamente maiores em ratos Wistar desnutridos. No estudo de Zamin-Junior et al. (2009) foi evidenciado que a ausência de colina e do aminoácido metionina na dieta acarretou o quadro de esteatose hepática em todos os animais estudados. No presente estudo a restrição utilizada impôs a deficiência de todos os nutrientes, inclusive os aminoácidos citados anteriormente. No entanto, no curto prazo em que se deu a desnutrição não foram observadas alterações histopatológicas difusas no tecido metabolicamente ativo do fígado.

Sendo assim, acredita-se que o aumento da massa do fígado em relação à massa corporal se deu devido ao curto prazo de desnutrição, que pode ter sido suficiente para diminuir a massa corporal, mas não para diminuir a massa do órgão.

Outra hipótese é a de que os animais estariam em fase inicial do quadro de esteatose hepática, e o curto prazo de desnutrição ainda não teria sido suficiente para proporcionar alterações histopatológicas difusas. A presença de acúmulo de gordura no interior de alguns vacúolos celulares, com característico deslocamento do núcleo do hepatócito para a periferia celular (estrutura conhecida como "anel de sinete"), reforça a hipótese mencionada (Figura 5B e 5C - em detalhe). As gotículas de gordura referidas, nas lâminas confeccionadas, são perdidas durante o processamento histológico e os vacúolos são identificados por um espaço em branco no interior da célula (imagem negativa). Além disso, observou-se a presença de um maior número de infiltrado mononuclear composto por linfócitos, plasmócitos e macrófagos no fígado dos animais desnutridos, em relação aos animais do grupo controle. Havendo ainda, hipertrofia das células de Kupffer (Figura 5 D e E - em detalhe).

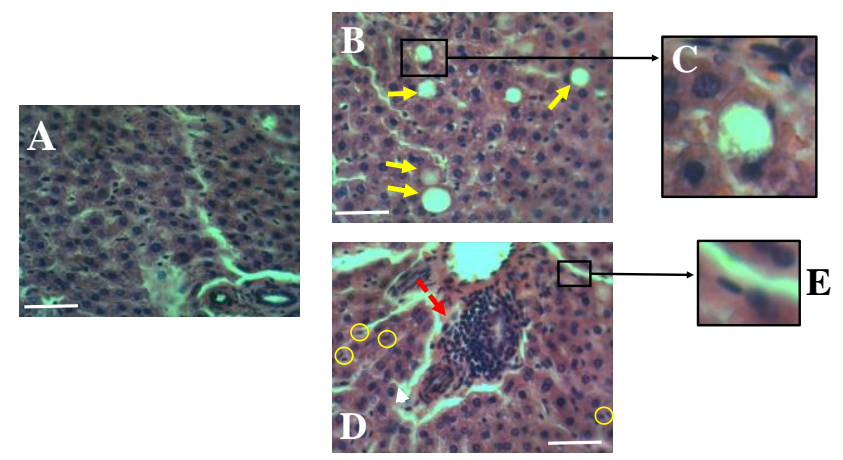

Figura 6: Fomicrografias dos cortes histológicos (HE) representativos do fígado dos animais controle (A) e desnutridos (B, C, D e E). Setas amarelas indicam acúmulo de gordura no interior de alguns vacúolos celulares periportais. Seta vermelha tracejada indica infiltrado inflamatório aleatório. Círculos indicam células de Kupffer. Barra $=100 \mu \mathrm{m}$. $(\mathrm{A}, \mathrm{B}$ e $\mathrm{D}=$ aumento $400 \mathrm{X})$.

Seguindo esta hipótese os resultados de Mazareti e Furlan (2008) e Zamin-Junior et al. (2009) seriam corroborados. No entanto, a ausência de análises histológicas no estudo de Mazareti e Furlan (2008) e até mesmo dos estudos citados na hipótese de quadro inicial de esteatose hepática, dificultam a elucidação de comparações mais específicas.

Quanto à massa relativa dos pulmões, esta foi maior, estatisticamente, nos animais desnutridos em relação aos animais do grupo controle, resultado que difere dos resultados encontrados por Malafaia et al. (2009), no qual os autores evidenciaram pulmões semelhantes entre os grupos. Entretanto, o modelo experimental utilizado pelos autores (camundongos Swiss) é diferente do utilizado no presente (ratos Wistar). Acredita-se que a massa relativa dos pulmões também esteja relacionada ao fato de que a desnutrição instalada em curto período teria sido suficiente para diminuir a massa corporal do grupo desnutrição, mas não seria suficiente para diminuir a massa desses órgãos.

Em relação às análises histológicas dos rins e baço, não foram observadas alterações histopatológicas (Figura 6). Acredita-se que estes resultados estejam relacionadas ao curto período de tempo em que os animais foram submetidos à condição de restrição alimentar.
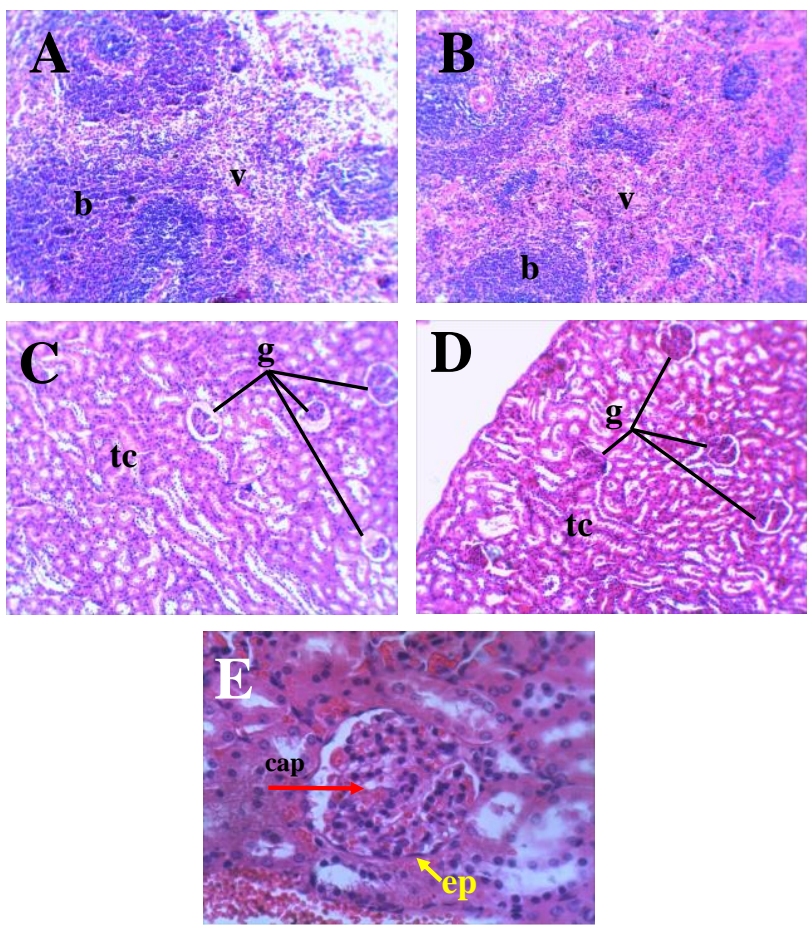

Figura 7: Fomicrografias dos cortes histológicos (HE) representativos do baço dos animais controle (A) e desnutridos (B), do rim (C, controle - D, desnutrido). (E) Detalhe da estrutura renal de um animal do grupo controle. "b" = polpa branca; " $\mathrm{v}$ " = polpa vermelha; " $\mathrm{tc}=$ túbulo contorcido; "g" = glomérulos; "cap" = capilar; "ep" = epitélio simples pavimentoso. (A,B C e D = aumento de $100 \mathrm{x}$ e $\mathrm{E}=$ aumento de 400x).

Quanto aos parâmetros bioquímicos, pode-se dizer que de modo geral poucos parâmetros sofreram alterações durante o período de desnutrição. Observou-se redução nas concentrações de triglicérides e de lipoproteínas VLDL (Tabela 2).

Tabela 2: Parâmetros bioquímicos dos animais estudados ${ }^{1}$

\begin{tabular}{lcc}
\hline $\begin{array}{l}\text { Parâmetros } \\
\text { Bioquímicos }\end{array}$ & $\begin{array}{c}\text { Grupo } \\
\text { Controle }\end{array}$ & $\begin{array}{c}\text { Grupo } \\
\text { Desnutrição }\end{array}$ \\
\hline Proteínas totais & $7,53 \pm(0,41)$ & $7,47 \pm(0,37)$
\end{tabular}

\begin{tabular}{lll} 
Albumina & $3,07 \pm(0,30)$ & $3,20 \pm(0,26)$ \\
\hline Globulinas & $4,46 \pm(0,29)$ & $4,27 \pm(0,36)$ \\
\hline Relação A/G & $0,69 \pm(0,08)$ & $0,76 \pm(0,10)$
\end{tabular}




\begin{tabular}{|lcc}
\hline Glicemia & $\begin{array}{c}59,86 \pm \\
(18,72)^{* *}\end{array}$ & $\begin{array}{c}124,00 \pm \\
(45,15)\end{array}$ \\
\hline Aspecto do soro & Límpido & Límpido \\
\hline Colesterol total & $97,57 \pm$ & $86,86 \pm(23,93)$ \\
mg/dL & $(26,98)$ & \\
\hline Triglicérides mg/dL & $109,14 \pm$ & $62,43 \pm(12,41)$ \\
& $(36,58)^{*}$ & \\
\hline HDL mg/dL & $50,71 \pm(9,11)$ & $48,57 \pm(8,89)$ \\
\hline LDL mg/dL & $25,00 \pm$ & $25,71 \pm(16,21)$ \\
& $(15,21)$ & \\
\hline VLDL mg/ dL & $21,83 \pm$ & $12,49 \pm(2,48)$ \\
& $(7,32)^{*}$ & \\
\hline Índice de Castelli (I) & $1,90 \pm(0,22)$ & $1,77 \pm(0,31)$ \\
\hline Índice de Castelli (II) & $0,46 \pm(0,25)$ & $0,51 \pm$ \\
\hline
\end{tabular}

$\overline{1}$ 10s dados apresentados são expressos em média \pm desvio padrão.

* Diferença significativa $(\mathrm{p}<0,05)$.

** Diferença significativa $(\mathrm{p}<0,01)$.

Trabalhos como o de Cisternas (2006) e Machado et al. (2008) demonstram a existência de uma correlação negativa entre glicemia e insulinemia. No fígado, a insulina inibe a glicogenólise, a gliconeogênese e a conversão de ácidos graxos e aminoácidos em cetoácidos. Além disso, aumenta a síntese de glicogênio, de triglicerídeos e de lipoproteínas VLDL (CISTERNAS, 2006; MACHADO et al., 2008).

Em estudos relacionados à desnutrição em longo prazo o declínio da produção de insulina (hipoinsulinemia) tem sido observado em alguns trabalhos como o de Fagundes et al. (2007) e Galdino et al. (2000). Galdino et al. (2000) observaram também que a liberação de insulina é reduzida em ratos alimentados com dieta hipoproteica, mas que esse efeito é compensado pela aquisição de maior sensibilidade dos tecidos alvo da insulina, o que permite manter a glicemia em níveis normais.

Embora não tenham sido dosados os teores séricos de insulina, a diminuição significativa $(\mathrm{p}<0,05)$ nos teores de triglicérides e lipoproteínas VLDL, que possuem correlação positiva com os teores de insulina, e a diminuição encontrada pelos autores citados anteriormente, permite inferir que a concentração de insulina no presente estudo era reduzida no grupo desnutrido.

Sendo assim, devido à possível baixa concentração de insulina, os teores elevados da glicemia encontrados no grupo desnutrido são explicados. Deste modo, a desnutrição em curto prazo foi suficiente para promover a diminuição dos teores de insulina, e consequentemente elevar os teores de glicose. Em contrapartida, o período curto não foi suficiente para que os animais adquirissem maior sensibilidade à insulina relatada por Galdino et al. (2000).

Quanto aos parâmetros hematológicos, foi verificada diferença significativamente menor no Volume Corpuscular Médio (VCM) e na concentração de leucócitos no grupo desnutrido (Tabela 3).

Tabela 3: Parâmetros hematológicos dos animais estudados ${ }^{1}$

\begin{tabular}{|c|c|c|}
\hline $\begin{array}{l}\text { Parâmetros } \\
\text { Hematológicos }\end{array}$ & Grupo Controle & $\begin{array}{l}\text { Grupo } \\
\text { Desnutrição }\end{array}$ \\
\hline Hemácias tera/L & $6,39 \pm(0,47)$ & $6,54 \pm(0,28)$ \\
\hline Hematócrito \% & $36,61 \pm(2,45)$ & $35,63 \pm(2,10)$ \\
\hline $\begin{array}{l}\text { Hemoglobinas g/ } \\
\text { dL }\end{array}$ & $15,26 \pm(1,23)$ & $14,30 \pm(0,49)$ \\
\hline VCM fl & $57,37 \pm(1,17)^{*}$ & $54,47 \pm(2,62)$ \\
\hline HCM pg & $23,97 \pm(2,39)$ & $21,89 \pm(1,14)$ \\
\hline CHCM g/ dL & $41,77 \pm(3,71)$ & $40,22 \pm(2,14)$ \\
\hline RDW \% & $13,27 \pm(0,48)$ & $12,73 \pm(1,20)$ \\
\hline Eritroblastos leuco & 0 & 0 \\
\hline Leucócitos mm³ & $\begin{array}{l}10.071,43 \\
(3.263,80)^{*}\end{array}$ & $\begin{array}{l}6.828,57 \\
(1.731,78)\end{array}$ \\
\hline Plaquetas & $\begin{array}{l}628.000,00 \pm \\
(354.016,01)\end{array}$ & $\begin{array}{l}543.285,71 \\
(278.408,40)\end{array}$ \\
\hline
\end{tabular}

${ }^{1}$ Os dados apresentados são expressos em média \pm desvio padrão.

* Diferença significativa $(\mathrm{p}<0,05)$.

A diminuição na concentração de leucócitos (leucopenia) tem sido encontrada por outros autores como Ferrari et al. (1992) e Santos et al. (2004), indicando que os animais desnutridos possuem o sistema imune debilitado, estando portanto, mais susceptíveis a infecções e doenças.

\section{Conclusão}

Diante do exposto, conclui-se que:

- $\quad 0$ protocolo de restrição alimentar utilizado foi capaz de induzir o quadro de desnutrição nos animais estudados:

- 0 curto período de restrição alimentar imposto não ocasionou alterações bioquímicas e hematológicas generalizadas nos animais estudados. Contudo, induziu o quadro de Leucopenia;

- $\quad$ A desnutrição imposta aos animais não foi capaz de ocasionar alterações histopatológicas difusas nos órgãos analisados.

Vale salientar que este estudo não tem caráter exaustivo e, portanto, sugere-se que novas pesquisas sejam desenvolvidas de modo a investigar variáveis não estudadas neste trabalho, assim como outras lacunas existentes que impedem a sistematização de conhecimento sobre o assunto.

\section{Referências}

ARAÚJO, E. J. A.; SANT'ANA, D. M. G.; MOLINARI, S. L.; MIRANDA-NETO, M. H. Effect of protein and vitamin B deficiency on the morpho-quantitative aspects of the myenteric plexus of the descending colon of adult rats. Arquivos de Neuropsiquiatria, São Paulo, v. 61, n. 2, p. 226-233, fev. 2003.

ARAÚJO, E. J. A.; SANT'ANA, D. M. G.; MOLINARI, S. L.; MIRANDA-NETO, M. H. Biometric and food consumption parameters of rats subjected to hypoproteic and hypocaloric diet. Arquivos de Ciências Veterinarias e Zoologia da UNIPAR, Umuarama, v. 8, n. 2, p. 133140,jul./dez. 2005. 
BORELLI, P.; BLATT, S.; PEREIRA, J.; MAURINO, B. B.; TSUJITA, M.; SOUZA, A. C.; XAVIER, J. G.; FOCK, R. A. Reduction of erythroid progenitors in protein-energy malnutrition. British Journal of Nutrition, Southampton, v. 97, n. 2, p. 307-314, fev. 2007.

BRASIL. Ministério da Saúde (MS). Programa de Combate às Carências Nutricionais - PCCN/ Ministério da Saúde. Brasília: Editora MS, 2001.

CABRAL, C. A. C. Efeitos do exercício físico em cardiomiócitos de ratos desnutridos. 2013. 62 f. Dissertação (Mestrado em Ciências Biológicas)- Universidade Federal de Ouro Preto, Ouro Preto, 2013.

CISTERNAS, J. R. Fisiologia das Ilhotas de Langerhans. In: DOUGLAS, C. R. Fisiologia aplicada à Nutrição. $2^{a}$ ed. Rio de Janeiro: Guanabara Koogan, p. 802-815, 2006.

CHAGAS, D. C.; SILVA, A. A. M. BATISTA, R. F. L. B.; SIMÕES, V. M. F.; LAMY, Z. C.; COIMBRA, L. C.; ALVES, M. T. S. S. B. Prevalência e fatores associados à desnutrição e ao excesso de peso em menores de cinco anos nos seis maiores municípios do Maranhão. Revista Brasileira de Epidemiologia, São Paulo, v. 16, n. 1, p. 146-156, jan. 2013.

CHAVES, M.G. de; MELLO, M.A.R. Metabolismo glicídico em músculo estriado esquelético de ratos em repouso submetidos à restrição proteica alimentar. Alimentação e Nutrição, Araraquara, v. 14, n. 1, p. 97-101, jan./jul. 2003.

DETSKY, A. S.; SMALLEY, P. S.; CHANG, J. Is this patient malnourished? JAMA, Chicago, v. 271, n. 1, p. 54-58, jan. 1994.

FAGUNDES, A. T.; MOURA, E. G.; PASSOS, M. C.; OLIVEIRA, E.; TOSTE, F. P.; BONOMO, I. T.; TREVENZOLI, I. H.; GARCIA, R. M.; LISBOA, P. C. Maternal low-protein diet during lactation programmes body composition and glucose homeostasis in the adult rat offspring. British Journal of Nutrition, Southampton, v. 98, n. 5, p. 922-928, nov. 2007.

FERRARI, F.; GABRIELLI, P. R. M.; MELLO, M. A. R. Restrição alimentar durante a gestação e suas implicações sobre o binômio mãe/feto. Um modelo experimental utilizando ratas jovens e adultas. Alimentação e Nutrição, Araraquara, v. 4, p. 45-56, jan./dez. 1992.

GALDINO, R.; ALMEIDA, C. C. S. LUCIANO, E.; MELLO, M. A. R. Protein malnutrition does not impair glucose metabolism adaptations to exercise-traning. Nutrition Research, Davis, v. 20, n. 4, p. 527-535, abr. 2000.

GERUDE, M. F.; AUGUSTO, A. L. P.; ALVES, D. C.; MANNARINO, I. C. Terapia Nutricional. São Paulo: Editora Atheneu, 2002.

LACERDA, E. M. A.; ACCIOLY, E.; FARIA, I. G. COSTA, V. M. Práticas de Nutrição Pediátrica. São Paulo: Editora Atheneu, 2006.

MACHADO, U. F.; CARPINELLI, A. R.; ZECCHIN, H. G.; SAAD, M. J. A. Pâncreas endócrino. In: AIRES, M. M. Fisiologia. 3a ed. Rio de Janeiro: Guanabara Koogan, p. 1032-1050, 2008.

MALAFAIA, G.; MARTINS, R. F.; SILVA, M. E. Avaliação dos efeitos, em curto prazo, da deficiência protéica nos parâmetros físicos e bioquímicos de camundongos Swiss. SaBios: Revista de Saúde e Biologia, Campo Mourão, v. 4, n. 2, p. 21-33, jul./dez. 2009.

MAZARETI, C. M.; FURLAN, M. M. D. P. Crescimento e parâmetros reprodutivos de ratas Wistar, em restrição alimentar desde o nascimento. Acta Scientiarum Biological sciences, Maringá, v. 30, n. 2, p. 197-204, abr./jun. 2008.
MINISTÉRIO DO DESENVOLVIMENTO SOCIAL E COMBATE À FOME. Educação Alimentar e Nutricional. Disponível em: <http://www.mds.gov.br/segurancaalimentar/sistema s-publicos-agroalimentares/educacao-alimentar-enutricional>. Acesso em: 10 fev. 2014.

MINITAB INC. Minitab Statistical Software, Release 14 for Windows [computer program]. Minitab $₫$ is a registered trademark of Minitab Inc. Pennsylvania, State College, 2003.

MOLINARI, L. M.; FERNANDES, C. A.; OLIVEIRA, L. R.; SANT'ANA, D. M. G.; MIRANDA-NETO, M. H. Nuronas Mioentéricas NADH-diaphorase positive myenteric neurons of the aglandular region of the stomach of rats (Rattus norvegicus) subjected to desnutrition. Revista Chilena de Anatomia, Temuco, v. 20, n. 1, p. 19-23, jan./abr. 2002.

MONTEIRO, C. A. A dimensão da pobreza, da desnutrição e da fome no Brasil. Estudos Avançados, São Paulo, v.17, n. 48, p. 7-20, maio/ago. 2003 .

MONTEIRO, C. A.; BENICIO, M. H. D. A.; KONNO, S. C.; SILVA, A C. F.; LIMA, A. L. L.; CONDE, W. L. Causas do declínio da desnutrição infantil no Brasil, 1996-2007. Revista de Saúde Pública, São Paulo, v. 43, n. 1, p. 35-43, jan./fev. 2009.

NUVITAL: Segurança em Nutrição Animal (2014). Disponível em: <http://www.nuvital.com.br/>. Acesso em: 10 jan. 2014.

OKAN, A.; ASTARCIOGLU, H.; TANKURT, E.; SAGOL, O.; ALTEKIN, E.; ASTARCIOGLU, I.; GONEN, O. Effect of ursodeoxycholic acid on hepatic steatosis in rats. Digestive Diseases and Sciences, Berlim, v. 47, n. 11, p. 2389-2397, nov. 2002.

OLINTO, M. T. A.; VICTORA, C. G.; BARROS, F. C.; TOMASI, E. Determinantes da desnutrição infantil em uma população de baixa renda: um modelo de análise hierarquizada. Cadernos de Saúde Pública, Rio de Janeiro, v. 9, p. 14-27, jan./mar. 1993.

OLIVEIRA, E.C. Avaliação bioquímica nutricional de animais treinados submetidos à desnutrição e recuperação nutricional. 2007. 139 f. Dissertação (Mestrado em Ciências Biológicas) - Universidade Federal de Ouro Preto, Ouro Preto, 2007.

PEDRAZA, D. F.; ROCHA, A. C. D.; SALES, M. C. Deficiência de micronutrientes e crescimento linear: revisão sistemática de estudos observacionais. Ciência e Saúde Coletiva, Rio de Janeiro, v. 18, n. 11, p. 3333-3347, nov. 2013.

PINHEIRO, A. R.; SALVUCCI, I. D.; AGUILA, M. B.; MANDARIMDE-LACERDA, C. A.; Protein restriction during gestation and/or lactation causes adverse transgenerational effects on biometry and glucose metabolism in F1 and F2 progenies of rats. Clinical Science, Portland, v. 114, n. 5, p. 381-392, mar. 2008.

RAHAMTALLA, F. A.; ELAGIB, A. A.; MAHDI, A.; AHMED, S. M. Prevalence of microalbuminuria among sudanese type 2 diabetic patients at elmusbah center at ombadda Omdurman. IOSR Journal of Pharmacy, v. 2, n. 5,p. 51-55, sep./out. 2012.

REEVES, P. G.; NIELSEN, F. H.; FAHEY-JUNIOR, G. C. AIN-93 purified diets for laboratory rodents: final report of the American Institute of Nutrition ad hoc writing committee on the reformulation of the AIN-76A rodent diet. Journal of Nutrition, Bethesda, v. 123, n. 11, p. 1939-1951, nov. 1993.

RITTER, L. L. N.; SANTOS, W. L. M.; RODRIGUES, J. G.; ALMEIDA, T. R.; BARBOSA-NETO, O. Treinamento físico por natação melhora perfil hepático em ratos Wistar tratados com 
dieta hipercalórica. Coleção Pesquisa em Educação Física, Jundiaí, v. 11, n. 2, abr./jun. 2012.

RODRIGUES, A. L.; MOURA, E. G.;PASSOS, M. C. F.; TREVENSOLI, I. H. T.; CONCEIÇÃO; E. P. S.; BONONO, I. T.; NOGUEIRANETO, J. F.; LISBOA, P. C. Postnatal early overfeeding induces hypothalamic higher SOCS3 expression and lower STAT3 activity in adult rats. Journal of Nutritional Biochemistry, Lexington, v. 22, n. 2, p. 109-117, fev. 2011.

SANTOS, H. B.; MADRUGA, M. S.; BION, F. M.; ANTUNES, N. L. M.; MENDES, K.; ÀGUIDA, R. Estudos bioquímicos e hematológicos em ratos sobre biodisponibilidade de minerais numa dieta enriquecida com multimistura. Ciência e Tecnologia de Alimentos, Campinas, v. 24, n. 4, p. 613-618, out./dez. 2004.

SAWAYA, A.L. Desnutrição: consequências em longo prazo e efeitos da recuperação nutricional. Estudos Avançados, São Paulo, v. 20, n. 58, p. 147-158, set./dez. 2006.

SILVA-GUSMAN, A. M. WANDERLEY, A. R.; MACÊDO, V. M.; BOAVENTURA, G. T. Recuperação da desnutrição em ratos mediante rações adicionadas ou não de suplemento alimentar e de vitaminas e minerais durante o período de crescimento. Revista de Nutrição, Campinas, v. 17, n. 1, p. 59-69, jan./fev. 2004.

TOMCZAK, A. C. T. Q.; GRILO, K. T. M.; CASTRO J. M.; MACHADO, A. M. B.; LEONART, M. S. S.; NASCIMENTO, A. J. Estudo de métodos laboratoriais para o controle de qualidade de unidades transfusionais eritrocitárias no Centro de Hematologia e Hemoterapia do Paraná (Hemepar), Brasil. Revista Brasileira de Hematologia e Hemoterapia, São José do Rio Preto, v. 32, n. 3, p. 209-214, maio/jun. 2010.

URTIAGA, G.; CAMPOS, V. F.;COLLARES, T. F.; LEON, P. M. M.; DESCHAMPS, J. C.; SEIXAS, F. K.; COLLARERS, T. Associação entre proteínas do plasma seminal, motilidade e viabilidade espermática em coelhos submetidos a doping genético. Arquivos Brasileiros de Medicina Veterinária e Zootecnia, Belo Horizonte, v. 65, n. 1, p. 75-81, jan./fev. 2013.

VISMARA, M. R.; FURLAN, M. M. Parâmetros biométricos como indicadores do grau de desnutrição em ratos sob restrição alimentar desde o nascimento. Arquivos de Ciências da Saúde da UNIPAR, Umuarama, v. 11, n. 1, p. 3-8, jan./abr. 2007.

WELTMAN, M. D.; FARRELL, G. C.; LIDDLE, C. Increased hepatocyte CYP2E1 expression in a rat nutritional model of hepatic steatosis with inflammation. Gastroenterology, Philadelphia, v. 111, n. 6, p.1645-1653, jun. 1996.

WORLD HEALTH ORGANIZATION (WHO). Malnutrition. Quantifying the health impact at national and local levels. Geneva: World Health Organization, 2005.

WORLD HEALTH ORGANIZATION - (WHO). Nutrition. 2011.

WORLD HEALTH ORGANIZATION (WHO). Malnutrition. Disponível em: <http://www.who.int/maternal_child_adolescent/topic s/child/malnutrition/en/index.html>. Acesso em: 15 jan. 2014.

XAVIER, J.G.; FAVERO, M. E.; VINOLO, M. A. R.; ROGERO, M. M.; DAGLI, M. L. Z.; ARANA-CHAVEZ, V. E.; BOROJEVIC, R.; BORELLI, P. Protein-energy malnutrition alters histological and ultrastructural characteristics of the bone marrow and decreases haematopoiesis in adult mice. Histology and Histopathology, Murcia , v. 22, n. 6, p. 651-660, jun. 2007.

ZAMIN-JUNIOR, I.; MATTOS, A. A.; MATTOS, A. Z.; MIGON, E.; SOARES, E.; PERRY, M. L. S. Modelo experimental de esteatohepatite não-alcoólica com dieta deficiente em metionina e colina. Arquivos de Gastroenterologia, São Paulo, v. 46, n. 1, p. 69-74, jan./mar. 2009.conditions. Science of the Total Environment, 530, 314-322.

Soil Survey Staff (2014). Keys to Soil Taxonomy, 12th ed. USDA-Natural Resources Conservation Service, Washington, DC.

Sposito, G. (1989). The Chemistry of Soils. New York, Oxford University Press.

Sumner, M.E. (1963). Effect of iron oxides on positive and negative charges in clays and soils. Clay Miner. Bull., 5, 218-226.

Tedesco, M.J., Volkweiss, S.J., and Bohnen, H. (1995). Análise de solo, plantas e outros materiais. Porto Alegre: Departamento de Solos. Faculdade de Agronomia. UFRGS (Boletim Técnico, 5). (in Portuguese)

Thompson, A., Chadwick, O.A., Rancourt, D.G., and Chorover, J. (2006). Iron-oxide crystallinity increases during soil redox oscillations. Geochimica et Cosmochimica Acta, 70, 1710-1727.

Vorenhout, M., Van der Geest, H.G., Van Marum, D., Wattel, K., and Eijsacker, H.J.P. (2004). Automated and continuous redox potential measurements in soil. J. Environ. Qual., 33, 1562-1567.

Wang, J., Muyzer G., Bodelier, P.L.E., and Laanbroek, H.J. (2009). Diversity of iron oxidizers in wetland soils revealed by novel 16S rRNA primers targeting Gallionella-related bacteria. The ISME Journal, 3, 715725.

Whittig, L.D.; Allardice, W.R. (1986). X-Ray Diffraction Techniques - Chapter 12. In.: Methods of Soil Analysis. Part 1 - Physical and Mineralogical Methods, ed. SSSA Book Series, n. 9, Wisconsin: SSSA. 